\title{
Conical Pick Production Process
}

\author{
Łukasz Bołoz, Antoni Kalukiewicz \\ AGH University of Science and Technology, Poland \\ Greg Galecki \\ Missouri University of Science and Technology, USA \\ Liubomyr Romanyshyn, Taras Romanyshyn \\ Ivano-Frankivsk National Technical University \\ of Oil and Gas, Ukraine \\ Rafael Barrionuevo Giménez \\ Escuela Técnica Superior de Ingeniería de Minas, Spain
}

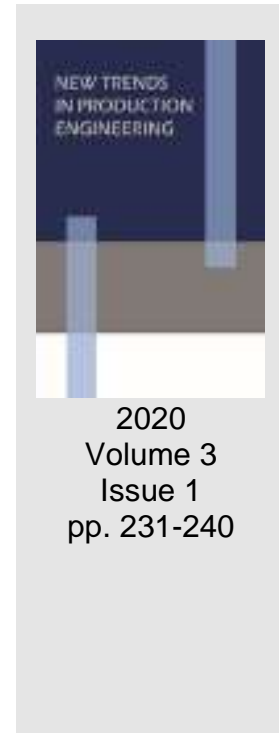

Date of submission to the Editor: 02/2020

Date of acceptance by the Editor: 03/2020

\section{INTRODUCTION}

Conical picks are more and more often applied in cutterheads. In difficult conditions and in the case of abrasive rocks mining, their life is considerably reduced. This translates into decreased operating efficiency and higher costs. Replacement of conical picks, which may be necessary even after a few hours, is particularly problematic. It should be noted that their number on the cutterhead is usually ca 40-60, and sometimes it can reach even more than one hundred pieces, hence the subject has a clear practical and economic dimension. Cutterheads are used as cutting elements for many machines in underground and opencast mining as well as in the construction industry, tunnel or road building.

Conical picks are the subject of research and development works carried out in many centres around the world. The investigations are mainly aimed at finding a solution with the highest abrasion resistance. Tests were conducted for picks with the body protected against abrasive wear by using abrasion resistant coatings, hardfacing or carbide rings (Chang \& Chulho, 2017). Works were carried out to explore the mechanism of abrasive wear and wear prediction (Gajewski et al., 2013) or the possibilities of assisting the mining process (Kotwica, 2011) and granulating the fine fractions (Sidor \& Feliks, 2015). Tests were done for cemented carbide (Nahak et al., 2015), steel (Gajdzik \& Sitko, 2014,2016 ) as well as for the complete pick (Songyong et al., 2017) or picks forming the cutting head (Krauze et al., 2015, Krauze \& Kotwica, 2007). Implementation works were also carried out with the aim of adjusting modern tools and machines to difficult conditions (Bołoz \& Krauze, 2018, Krauze \& Bołoz, 2018) as well as using alternative tools in the form of discs (Gospodarczyk et al., 2013, 2016, Anchor, 2018, Bołoz, 2019). The subject 
of works was also the procedure for assessing the quality of picks enabling the user to choose the best offer in public tenders (Bołoz, 2018).

The article describes the method of producing conical picks using turning as the basic process and die forging.

\section{CONICAL PICKS}

The standard conical pick in the form of a solid of revolution is made of a working part and a gripping part formed by a cylindrical one- or two-stage mandrel, as well as a tip in the form of a cemented carbide insert (Fig. 1a). The conical picks of the cutting heads are mounted directly in pick holders or in sleeves, which are additional intermediate elements between the holder and the pick. The holder may also have an integrated sleeve made of a high performance material. The shape of the picks and the appropriate way of mounting them in the holder result from the need for their free rotation relative to the axis of symmetry, the effect of which in an even wear of the tip. Uniform wear and simultaneous shortening of the working part of the pick ensure correct static and dynamic friction cutting angles. The body and the gripping part constitute one element made of steel characterised by appropriate impact resistance $\left(U_{\min } \approx 25 \mathrm{~J} / \mathrm{cm}^{2}\right)$, tensile strength $\left(R_{m} \min \approx 1000 \mathrm{MPa}\right)$ and abrasive wear resistance. It is recommended that the working part of the body should have a hardness measured by Rockwell of minimum $45 \mathrm{HRC}$, whereas the gripping part hardness, due to the risk of holder damage, should be within the range of $30 \mathrm{HRC} \pm 5 \mathrm{HRC}$. Depending on the purpose of the tool, it is made of $12 \mathrm{HN} 3 \mathrm{~A}, 40 \mathrm{H}, 40 \mathrm{HN}, 36 \mathrm{HNM}$ or $35 \mathrm{HGS}$ types of steel, which are additionally subjected to a thermal and chemical treatment in order to improve the abrasion resistance of the surface layer. Optional abrasion resistant layers are made of stellites or cemented carbides based on cobalt, nickel or iron. Electrodes in the form of powders, rods or tubes with powders are used for hard facing. The coatings' hardness can reach more than $60 \mathrm{HRC}$
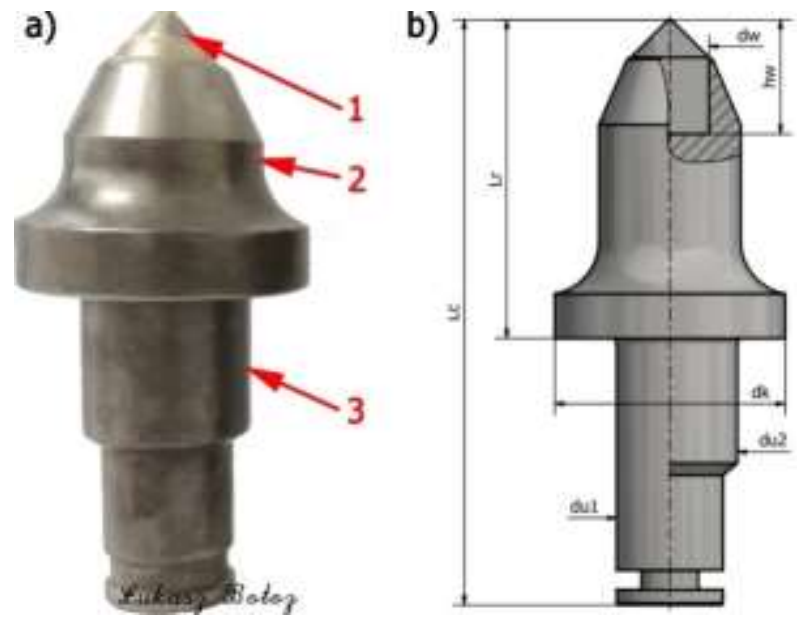

Fig. 1 Construction and basic dimensions of the conical pick a) construction of the pick, b) basic dimensions of the pick 
The tip is made of various kinds of cemented carbide characterized by high hardness, which should reach at least $\mathrm{HV}_{30}$ min $\approx 1050$ on the Vickers scale. Irrespective of the grade, typical mining cemented carbides belonging to group $\mathrm{B}$, in $89 \%-93 \%$ consist of hard, abrasion resistant tungsten carbide WC, whereas the remaining part is cobalt $\mathrm{C}$, which is a binding phase. Cemented carbide is soldered into the socket in the working part of the pick's body. B2, B20, B23, G15 and other carbides with similar chemical compositions and properties are most commonly used to reinforce conical picks.

Important parameters influencing the proper course of the cutting process are the geometrical and kinematic parameters of the pick in the holder and the cutting head of the machine. Based on the analysis of available conical picks, mainly in longwall shearers and road headers, a summary of their parameters has been prepared (Fig. 1b):

- total length of pick: $L_{c}=139-246 \mathrm{~mm}$,

- length of pick's working part: $L_{r}=50-100 \mathrm{~mm}$,

- diameter of pick's gripping part: one-stage: $\mathrm{du}_{\mathrm{u}, 2}=\phi 30 \mathrm{~mm}, \phi 35 \mathrm{~mm}, \phi 38 \mathrm{~mm}$, two-stage: $\phi 30 / 38 \mathrm{~mm}$,

- diameter of pick's flange: $d_{k}=\phi 48-\phi 67 \mathrm{~mm}$,

- method of pick mounting (Fig. 2): Seger ring, HERT split pin, expanding ring, friction ring,

- diameter of cemented carbide insert: $d_{w}=\phi 13-\phi 25 \mathrm{~mm}$,

- height of cemented carbide insert: $h_{w}=14-40 \mathrm{~mm}$,

- tip angle: $2 \beta \mathrm{u}=90^{\circ}, 93^{\circ}$, more than $100^{\circ}$ for ballistic shape,

- shape of tip: conical, multiconical, ballistic, hat-shaped.

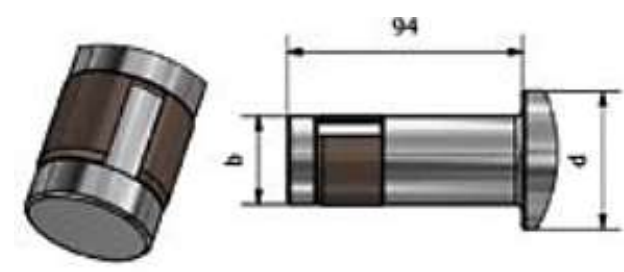

PC - pierścień cierny

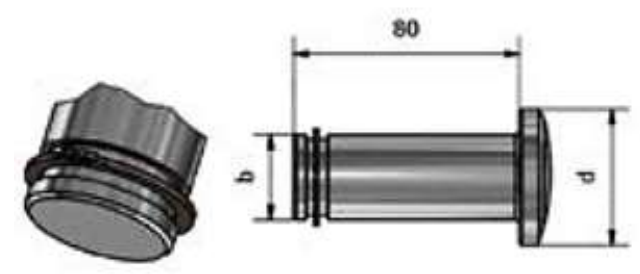

PS - pierścień segera

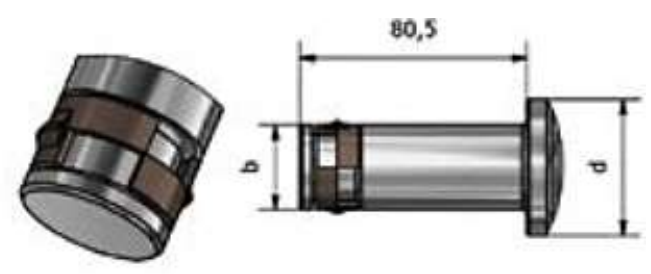

PR - pierścień rozprężny

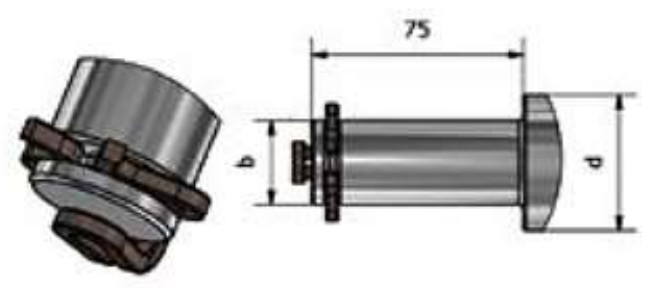

$\mathrm{ZH}$ - zawleczka hert Source: (Carbonex, 2020)

Fig. 2 Methods of securing the conical pick in the holder

There are many different pick models for the above quoted values and methods of mounting. However, it should be noted that the working part of the pick may have various shapes, the examples of which have been presented in Fig. 3. This results in the existence of more than two hundred models of picks. 


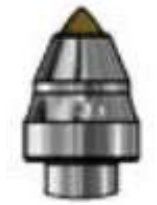

G1

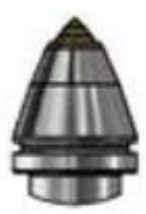

G7

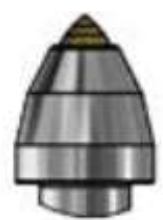

G2

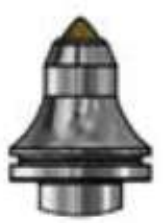

$\mathrm{G} 8$

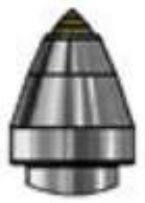

G3

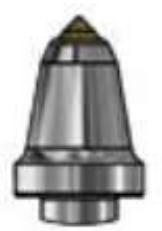

G9

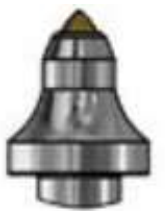

G4

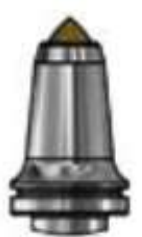

G10

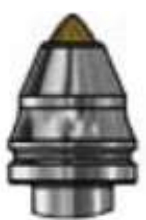

G5

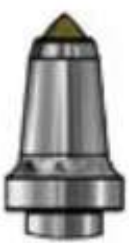

G11

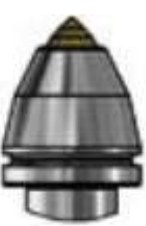

G6

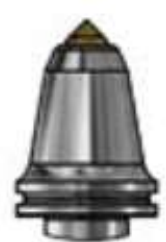

G12

Source: (Carbonex, 2020)

\section{TURNING OF PICKS}

Due to the large diversity of geometry and size of picks, using a universal method of their production seems justified. Therefore, machining by turning as the basic production process is widely applied. The technology of the production of picks described in this chapter has been developed by ZWM Carbonex (CX, 2020).

The production of conical picks is preceded by the design and technical documentation based on the requirements of the future user (Fig. 3a).

a)

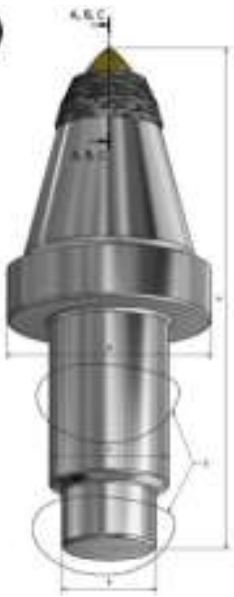

b)

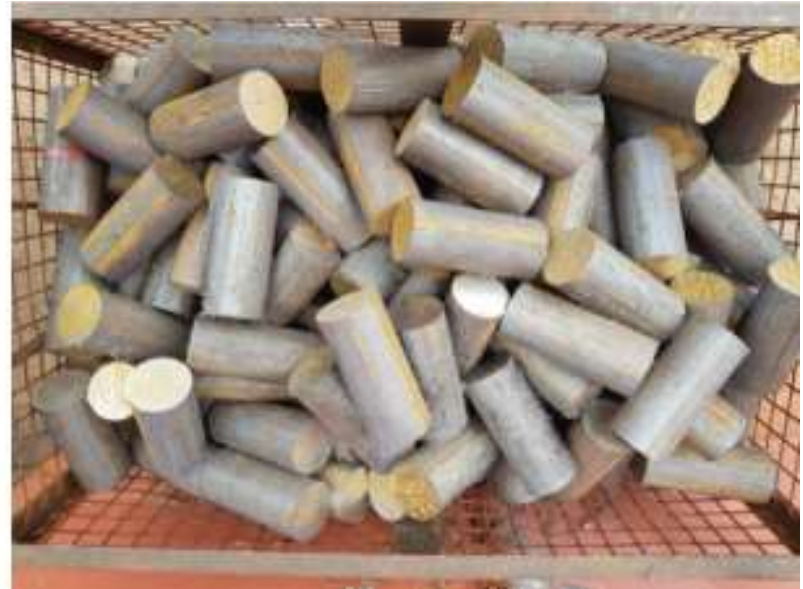

Fig. 3 Stages of the production of picks:

Conical picks, being an inseparable element of the cutting head, must meet a number of requirements, so their parameters are verified in terms of the parameters of the mining machine on which they will be mounted, the properties of the rock mass and broadly defined working conditions. Additional requirements regarding the reinforcement of the working part with coatings or rings are also being agreed.

Logistically, these activities are carried out in parallel with the implementation of orders for production materials. Generally, the production of picks can be divided into: steel selection, cutting into semi-finished products, body turning, tip soldering, thermal treatment and optional hard facing. The body of conical picks 
to be used in shearers is made of steel which must have appropriate properties. The most important is abrasion resistance, obtained by achieving the desired hardness of the body in the heat treatment process. At this stage, also rods of appropriate diameter are ordered, enabling the largest part of the pick body to be made, i.e. the flange of the working part ( $d_{k}$ in Fig. 1). Steel bars are cut with a saw into semi-finished products (Fig. 3b). A shaft of a suitable diameter is guided onto the saw feeders and cut to the desired length according to the technical documentation ( $L_{c}$ in Fig. 1), taking into account the necessary allowance for the facing of front surfaces. The number of pieces cut corresponds to the number specified in the order, plus a few pieces for potential technological waste during production.

The next stage, i.e. turning the pick body, takes place in two steps. First, the gripping part of the pick is subjected to turning (Fig. 4a). A lathe is prepared, appropriate tools and settings are chosen based on the selected program and the technical drawing of the pick. The next step involves turning the second half of the body, called the working part (Fig. 4b). The machine is prepared in the same way as in the case of shank treatment. When setting the lathe, special attention is paid to the dimensions of the opening for cemented carbide, which should be adjusted to the shape and diameter of the insert, while maintaining an appropriate soldering gap dependent on the type of soldering process chosen by the technologist. The treatment is finished with marking the extruded bodies in a given batch, which are then transported to the soldering process.

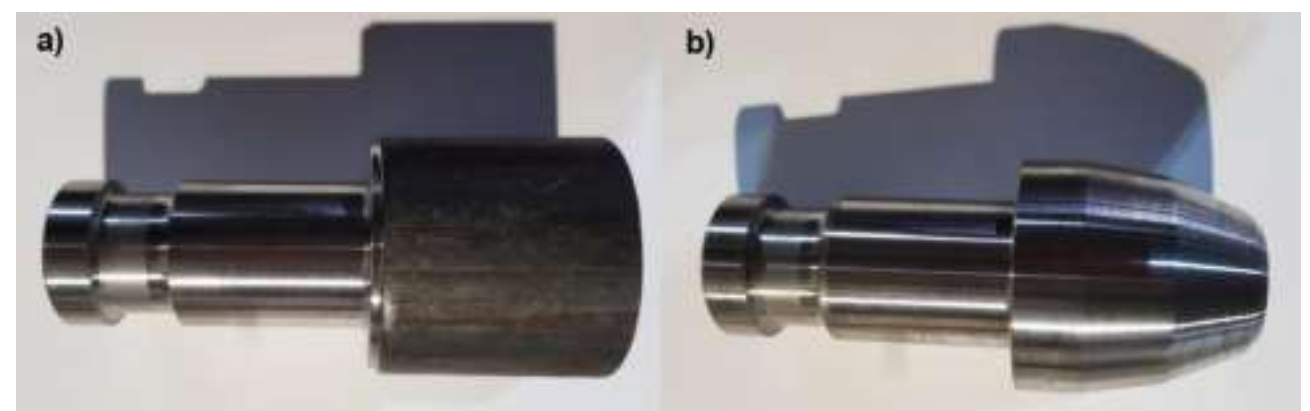

Fig. 4 Stages of turning:

a. extruded gripping part of the pick, b. ready-made steel body of the pick

The process of carbide soldering begins with a series of preparatory activities that affect the final quality of the picks. This process consists in permanently merging the body with cemented carbide. Soldering takes place at a special workstation (Fig. 5a).

The table height relative to the inductor is set for a given pick size. The flux used for soldering has the form of paste and is adjusted to the production technology of a given pick, the proper grade of hard solder and a cemented carbide insert in accordance with the developed technical documentation. For soldering the following are used: a flux in the form of paste, selected according to the production technology of a given pick, hard solder of appropriate grade and a cemented carbide insert in accordance with the developed technical documentation. In order to provide a sufficient quality of the connection, the 
socket for embedding the carbide must be clean, free of chips and rust. Next, the parameters of the soldering machine are selected and set. The power of the soldering furnace is adjusted to the inductor of a given diameter, shape and the number of coils.
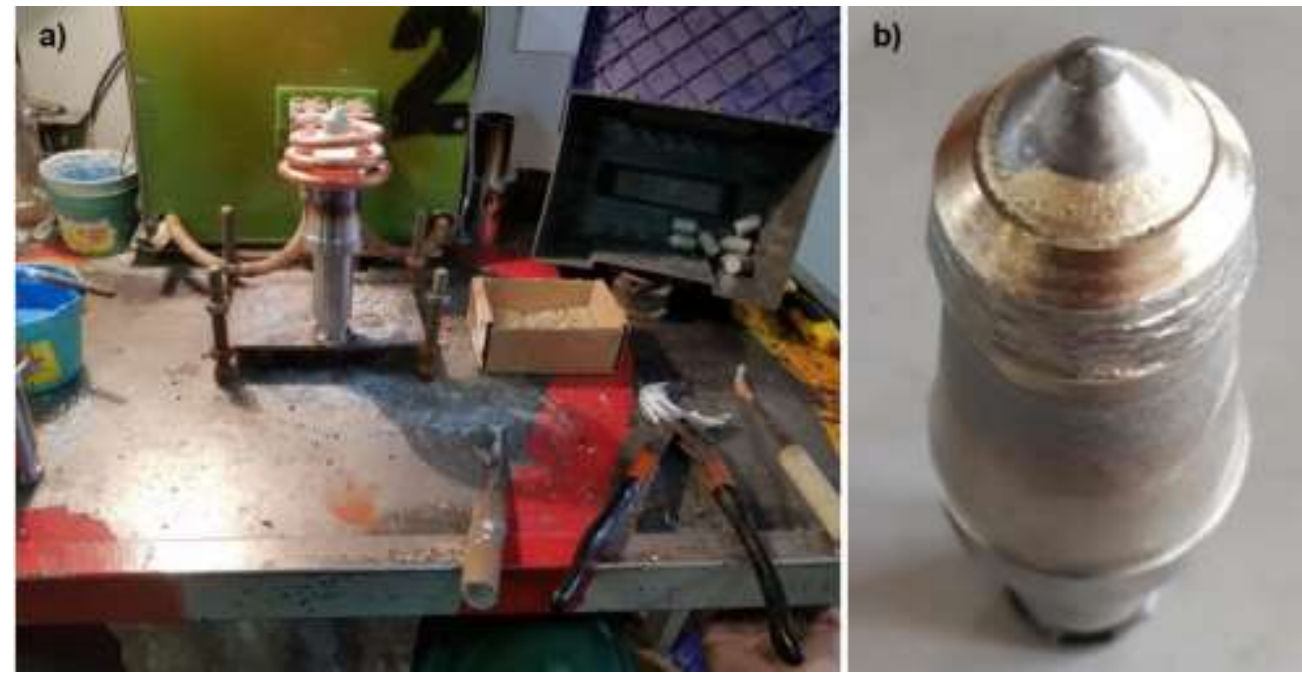

Fig. 5 Stages of the production of picks:

a. solderer's workstation, b. pick with a wear resistant padding weld

The accuracy of the connection also depends on the experience of the worker who, in addition to monitoring parameters and controlling the heating time of the soldering unit, is responsible for maintaining the appropriate carbide pressure. The soldering process and the next stage, i.e. heat treatment, can be performed in reverse order, depending on the required tool parameters.

The technology of conical picks heat treatment has many variants, but it usually involves hardening and tempering. The parameters of the hardening and tempering process were developed on the basis of tests using a workpiece temperature recorder during thermal treatment operations. These parameters are selected taking into account the grade of steel used to make the pick body, the desired hardness of the finished product and other parameters, such as the expected impact strength. Conical picks are exposed to frequent impacts and work under variable dynamic loads. Therefore, the key is to achieve high wear resistance and high impact strength, which in practice means a compromise between these properties. The following are used to carry out the heat treatment process: resistance electric furnaces with appropriate parameters, hardening baskets and a hardening bath filled with a coolant. The picks are transported and thermally treated in heat-resistant baskets, which facilitate their transport and ensure uniform heating and cooling. Due to the diversity of picks, the heat treatment parameters are selected each time. The picks are placed in the chamber of a preheated hardening furnace. The picks in the furnace are first heated, and after reaching the desired temperature, annealed so as to achieve the appropriate phase changes of steel. The entire process lasts from 1 hour to 1.5 hours. This time is chosen to ensure uniform distribution of temperature in the cross-section of the pick and to avoid hardening deformations. Keeping 
the tools in the furnace causes a reduction in the strength and plasticity limit with low impact strength at the same time. The next step is hardening, i.e. cooling the picks in a tank with a selected cooling medium. The picks remain immersed in the mixture until all beneficial and desired changes occur in the steel structure. The most important parameter is the rate of temperature change in steel and the final temperature value. Next, the whole batch goes to another furnace, where the tempering process takes place so as to eliminate stresses generated during hardening. As a result of this operation, the steel hardness is slightly reduced; however, the tensile strength remains high and the impact strength is increased. The setting of furnace parameters depends on the results of the previous process. The tempering process lasts approximately 1 hour. Then, depending on the steel grade, the picks are cooled in the open air or in a liquid with pre-set parameters.

One of the methods of increasing the body's resistance to abrasion is hard facing with abrasion-resistant materials. The accelerated wear of the steel body causes a rapid loss in the pick's functionality. Depending on the type of padding weld, target tool parameters and technological limitations, the hard facing process may take place before the soldering process, after soldering, but before heat treatment, as well as at the end of the pick production process, i.e. after heat treatment. The hard facing process is fully automated. The hard facing machine parameters and welding wire thickness are set precisely to match the body size and the steel grade it is made of. The reinforcement made is characterized by high hardness and high resistance to abrasive wear, which positively affects the working time of the pick (Fig. 5b).

Picks must meet strict technical requirements, but it is also important to maintain the highest aesthetic values. That is why ready-made picks go to the cleaning machine, which removes dirt from the surface. Next, the required marking is made to enable efficient batch identification. The marking is also used in the event of a complaint. In addition, the picks are painted to protect them against corrosion. To facilitate storage and subsequent transport to the customer, the cutting tools are packed into plastic boxes and everything is palletized.

\section{FORGING OF PICKS}

For large quantities of picks of a given model, the die forging technology is used to make the semi-finished product. Górnicza Fabryka Tool Tools Sp. z o.o. is involved in the production of forgings, including forgings for conical picks (GFN, 2020). As in the case of the previously described production based on turning, the process begins with cutting steel bars, mainly with band saws. Next, the workpieces are heated in induction heaters to the value specified in the material's safety data sheet. $41 \mathrm{Cr} 4$ steel is usually used. After heating, the workpiece is inserted into forging tools mounted on a screw friction press. The key stage is stamping the forgings. After the forging operation, the forging is removed and put into a pallet. After cooling down, it is subjected to shot blasting so as to remove the unfavourable scale, which causes wear of the cutting tools. As a result, a forging with a pre-set shape and dimensions 
is obtained (Fig. 6a). Then, the forging is subjected to machining (Fig. 6b). The subsequent stages are consistent with the previously described ones.

The material subjected to the process of forging obtains better physical and mechanical properties. Fibre continuity is maintained, which guarantees the forging's resistance to the highest loads and high resistance to plastic deformation and cracking. Forging enables obtaining complicated shapes (Fig. 6c) and a shape similar to that of the finished product, which results in significant material savings and reduced machining costs. The treatment of certain surfaces can be completely given up, and where it is necessary, the allowances are minimal.

a)

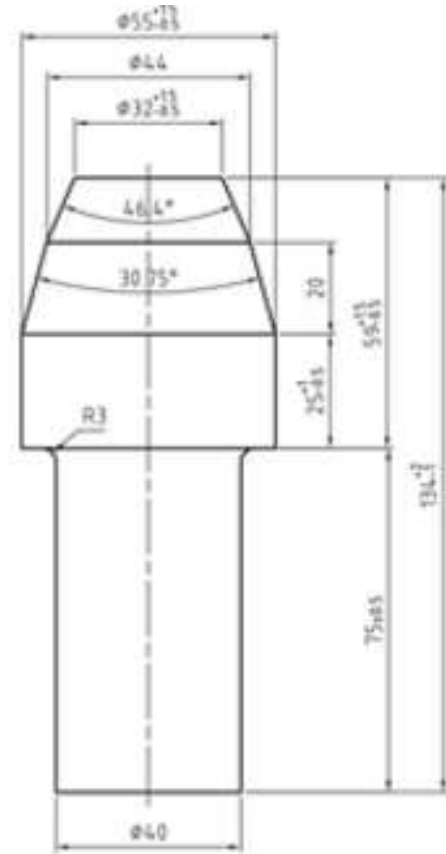

b)

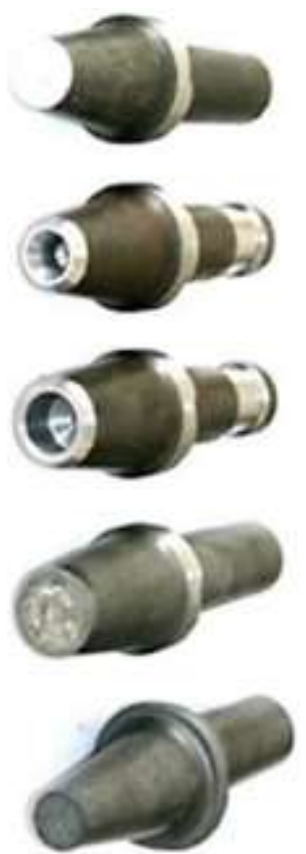

c)

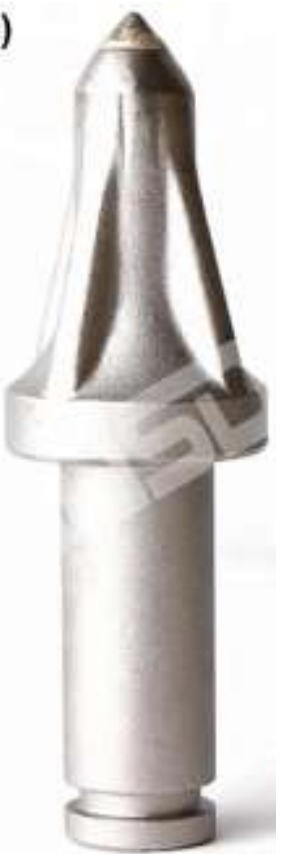

Fig. 6. Forged picks:

a. drawing of a pick forging (GFN), b. forgings and stages of treatment (Chinese company Sunway Forging), c. forged pick (Chinese company BAUSDE)

\section{CONCLUSIONS}

The cutting of rocks with conical picks, especially in difficult and demanding conditions, entails their rapid wear and the need for frequent replacement. The underground mining branch in Poland mostly relies on mechanical rock mining, where conical picks play a significant role. The value of the Polish market of mining tools, including conical picks, reaches tens of millions of zlotys annually. The large diversity of geometry and dimensions of these tools justifies the application of turning technology in the case of small production runs. Alternatively, for large production runs, it is preferable to use free forging, where the forging obtained requires slight machining. The presented processes involved in the production of picks in ZWM Carbonex and GFN are currently the only ones applied in practice. 


\section{REFERENCES}

Bołoz $\nvdash$, Krauze K. (2018). Ability to mill rocks in open-pit mining. In: $18^{\text {th }}$ International Multidisciplinary Scientific Geoconference, Exploration and Mining, SGEM2018, Albena, Bulgaria, Voulme 2, pp. 41-48.

Bołoz Ł. (2019). „Directions for increasing conical picks' durability”, in New Trends in Production Engineering: Monograph. Pt. 1, Engineering and technology, ed. Krzysztof Kotwica, Warszawa, Sciendo, pp. 277-286.

Bołoz $Ł$. (2018). „Results of a study on the quality of conical picks for public procurement purposes", in Proceedings of the international conference on Human safety in work environment: operating machinery and equipment: integrated management systems: Quality - Environment - Safety, 23-27 October 2018, GdańskNynashamn-Sztokholm-Tallin-Sztokholm-Nynashamn-Gdańsk, pp. 687-693.

Chang S., Lee, Chulho, Kang. (2017). Tae-Ho Effect of hard facing on wear reduction of pick cutters under mixed rock conditions. Geomechanics and engineering, 13(1), pp. 141-159.

Zakład Wyborów Metalowych „CARBONEX”, http://www.zwmcarbonex.pl, 19.02.2020.

Dewangan, Saurabh, Chattopadhyaya, Somnath, (2015). Critical Analysis of Wear Mechanisms in Cemented Carbide. Jorunal of Materials Engineering and Performance, 24(7), pp. 2628-2636.

Gajewski J., Jedlinski L., Jonak J. (2013). Classification of wear level of mining tools with the use of fuzzy neural Network. Tunnelling and Underground Space Technology, 35, pp. 30-36.

GFN, Górnicza Fabryka Narzędzi Sp. z o.o., http://www.gfn.com.pl, (19.02.2020),

Gospodarczyk P, Kotwica K., Mendyka P., Stopka G. (2016). Innovative roadheader mining head with assymetrical disc tools, Exploration and Mining, Mineral Processing. International Multidisciplinary Scientific GeoConference SGEM, Sofia, 2, pp. 489-496.

Gospodarczyk P., Kotwica K., Stopka G. (2013). A new generation mining head with disc tool of complex trajectory, Archives of Mining Sciences, 58(4), pp. 985-1006.

Kotwica K. (2011). The influence of water assistance on the character and degree of wear of cutting tools applied in road headers. Archives of Mining Sciences, 5(3), pp. 353-374.

Kotwica K. (2018). Atypical and innovative tool, holder and mining head designed for road headers used to tunnel and gallery drilling in hard rock. Tunnelling and Underground Space Technology, 82, pp. 493-503.

Krauze K., Bołoz Ł. (2018). Disc unit dedicated to mine abrasive rocks and in particular copper ores. In: $18^{\text {th }}$ International Multidisciplinary Scientific Geoconference, Exploration and Mining, SGEM2018, Albena, Bulgaria, Voulme 2.

Krauze K., Bołoz $Ł$., Wydro T. (2015). Parametric factors for the tangential-rotary picks quality assessment, Archives of Mining Sciences, 60(1), pp. 265-281.

Nahak, Sakuntala; Dewangan, Saurabh; Chattopadhyaya, Somnath. (2015). Discussion on Wear Phenomena in Cemented Carbide. In: Global Challenges, Policy Framework \& Sustainable Development for Mining of Mineral and Fossil Energy Resources. Dhanbad: GCPF, 11, pp. 284-293.

Prokopenko S. A., Vorobiev A. V., Lyudmila A., Janocko J. (2018). Waste Cutters Utilization in Underground Coal Mining, Acta Montanistica Slovaca, 23(1), pp. 81-89.

Songyong L., Huifu; J., Xiaohui L. (2017). Experimental research on wear of conical pick interacting with coal-rock. Engineering failure analysis, 74, pp. 172-187.

Gajdzik B., Sitko J. (2014). An analysis of the causes of complaints about steel sheets in metallurgical product quality management systems. Metalurgija, 53(1), pp. 135-138.

Gajdzik B., Sitko J. (2016). Steel mill products analysis using qualities methods Metalurgija, 55(4), pp. 807-810. 


\begin{abstract}
.
One of the basic methods of mechanical rock mining is cutting, which faces increasingly difficult working conditions. Despite the rapid development of machines used in underground and opencast mining as well as in tunnel building, construction industry and road engineering, the problem of insufficient durability of mining tools remains unsolved. In addition to drilling and, to a lesser extent, planing, cutting provides a huge market for tools. Currently, the process of cutting is mainly based on conical picks. The cutterheads of cutting machines are equipped with several dozen, and frequently - more than one hundred conical picks, which, due to their workability and abrasiveness, sometimes work only a few hours. There is a market demand for over two hundred models of conical picks. This is due to the huge variety of shapes and sizes of picks as well as the methods of their mounting in the holder. The article briefly presents various solutions of conical picks, their construction, methods of protection, dimensions and materials used. Next, based on materials produced by ZWM Carbonex, the classic method of their manufacture using the turning technology has been described. The authors have also presented briefly the use of die forging for the large-scale production of picks, applied by Górnicza Fabryka Narzędzi Sp. z o.o.
\end{abstract}

Keywords: conical picks, cutting, production of picks, pick turning, die forging 